\title{
Effects of Diabetes on Lipid Peroxidation and Scavenger Activity in Ischemia/Reperfusion Injury
}

\author{
Koichi Nonoda, M.D., Tatsuaki Matsubara, M.D., \\ Masaaki Kanashiro, M.D., Osamu SuzuKi, M.D., \\ Masahide NAKAO, M.D., \\ and Nobuo Sakamoto, M.D.
}

\begin{abstract}
Summary
This study examined the effects of ischemia/reperfusion on cardiac function and diabetes-associated lipid peroxidation and scavenger induction in isolated working hearts. Cardiac function in diabetic rats was depressed in proportion to the duration of diabetes. Plasma levels of malondialdehyde (MDA) were increased significantly after diabetes of 1 -week duration (1wD). MDA levels in the myocardium were increased significantly after 4-weeks $(4 \mathrm{wD})$ and tissue superoxide dismutase (SOD) activity was also elevated significantly in 8-week diabetic rats $(8 \mathrm{wD})$ as compared to control values. In both controls and diabetics, tissue MDA concentrations increased significantly during the first $3 \mathrm{~min}$ of reperfusion following $20 \mathrm{~min}$ of ischemia, compared with preischemia levels. At the end of reperfusion, tissue MDA levels decreased in controls and $1 \mathrm{wD}$ hearts, but remained elevated in the $4 \mathrm{wD}$ and $8 \mathrm{wD}$ cases. The SOD activity in $8 w \mathrm{D}$ hearts decreased significantly after $20 \mathrm{~min}$ of global ischemia followed by $30 \mathrm{~min}$ reperfusion, compared with preischemia levels. By contrast, there were no significant differences between preischemic and after-reperfusion data for parameters of cardiac function in $8 \mathrm{wD}$ rats. Thus, lipid peroxidation appears to have little influence on cardiac function during ischemia/reperfusion in rats with chronic diabetes. (Jpn Heart J 34: 591-599, 1993)
\end{abstract}

\section{Key Words:}

Diabetes Ischemic/reperfused rat heart

Superoxide dismutase Cardiac function

Malondialdehyde

\footnotetext{
YARDIOVASCULAR disorders, especially acute myocardial ischemia, are 1 frequently associated with diabetes. Oxygen radical formation has been found to induce acute myocardial damage, ${ }^{1,2)}$ and some reports suggest that free radical-medicated reactions may also be involved in the pathogenesis of microangiopathy in diabetes. ${ }^{3,4)}$ However, the role of oxygen radical formation in acute myocardial damage in diabetic hearts has not been investigated.

From the Third Department of Internal Medicine, Nagoya University School of Medicine, Nagoya, Japan. Address for correspondence: Tatsuaki Matsubara, M.D., Third Department of Internal Medicine, Nagoya University School of Medicine, 65 Tsuruma-cho, Showa-ku, Nagoya 466, Japan.

Received for publication February 26, 1993.

Accepted April 9, 1993.
} 
This study examined changes in the concentration of malondialdehyde (MDA), an index of lipid peroxidation, and the activity of superoxide dismutase (SOD), responsible for free radical scavenging, under various conditions in working diabetic rat heart preparations. We also assessed cardiac function before ischemia and during ischemia/reperfusion to determine relationships with tissue levels of MDA and SOD.

\section{Materuals ANd Methods}

\section{Animals}

Diabetes was induced in male Wistar rats by an intravenous injection of streptozotocin (Sigma Chemical Co., St. Louis, MO, USA) at a dose of $50 \mathrm{mg} /$ $\mathrm{kg}$. Diabctic rats were injected with streptozotocin at 15 weeks (1-weck diabetic rats), at 12 weeks (4-week diabetic rats), or at 8 wccks (8-week diabetic rats) of age. Rats with a serum glucose concentration below $300 \mathrm{mg} / \mathrm{d} l$ were excluded. Control rats were allowed to develop normally and received a single tail-vein injection of an equal volume of citrate buffer. All animals were sacrificed at 16 weeks of age.

\section{Perfusion methods}

Rats were anesthetized with an intraperitoneal injection of sodium pentobarbital $(50 \mathrm{mg} / \mathrm{kg})$. Thirty seconds later, hearts were excised quickly and placed in a cold perfusion medium until contractions ceased. Each heart was then perfused through the aorta on a noncirculating Langendorff apparatus, operating at a constant pressure $(75 \mathrm{~cm}$ of water) with a nonprotein KrebsHenseleit bicarbonate buffer $\left(37^{\circ} \mathrm{C}, \mathrm{pH} 7.4\right)$ oxygenated with $95 \% \mathrm{O}_{2}-5 \% \mathrm{CO}_{2}$. Perfusate containing (in mmol/l) $118.0 \mathrm{NaCl}, 4.7 \mathrm{KCl}, 2.5 \mathrm{CaCl}_{2}, 1.2 \mathrm{MgSO}_{4}$, $1.2 \mathrm{KH}_{2} \mathrm{PO}_{4}, 25.0 \mathrm{NaHCO}_{3}, 0.5 \mathrm{Na}_{2} \mathrm{EDTA}$, and 5.5 glucose was filtered through a membrane with a 5- $\mu \mathrm{m}$ pore size before use. The hearts were then switched to a working-heart apparatus which has been described previously $y^{5}$ and allowed to stabilize for $15 \mathrm{~min}$ in this recirculating system. The height of the left atrial reservoir was set to maintain a pressure of $10 \mathrm{~cm} \mathrm{H}_{2} \mathrm{O}$ and the aortic column to maintain a pressure of $75 \mathrm{~cm} \mathrm{H}_{2} \mathrm{O}$ at all times. Only preparations displaying a sinus rate of at least 200 beats $/ \mathrm{min}$, a coronary flow of at least $9 \mathrm{~m} / / \mathrm{min}$, and the absence of arrhythmias $5 \mathrm{~min}$ before ischemia were used in this study.

Global ischemia was induced by cross-clamping the aortic perfusion tube and left atrial cannula for $20 \mathrm{~min}$ at $37^{\circ} \mathrm{C}$. The preparation was then reperfused with the same oxygenated buffer. If ventricular fibrillation occurred during the reperfusion state, the heart was cxcluded from the data analysis. 


\section{Physiological measurements}

Electrocardiograms were recorded via two silver electrodes attached to the ventricular apex and the aortic cannula. Coronary flow was measured by collecting the effluent and aortic output was measured with an electromagnetic flowmeter (Nihon Kohden, Tokyo, Japan). A polyethylene catheter was placed into the left ventricle via the left atrium to measure the left ventricular systolic pressure (LVSP) and left ventricular end-diastolic pressure (LVEDP). Heart rate and left ventricular pressure were recorded with a transducer and polygraph system (Nihon Kohden). Individual hearts were frozen in liquid nitrogen and metabolic parameters measured before ischemia, after the first $3 \mathrm{~min}$ of reperfusion, or $30 \mathrm{~min}$ after reperfusion.

\section{Metabolic measurements}

The concentration of MDA, a lipid peroxidation product, was measured in heart homogenates by the thiobarbituric acid test. ${ }^{6)}$ Optical density was determined at $532 \mathrm{~nm}$. SOD activity was determined according to the luminescence method using a Cypridina luciferin analog, CLA [2-methyl-6-phenyl-3, 7 dihydroimidazo (1, 2a) pyradin 3-one] (Sigma Chemical Co.). ${ }^{7}$ The standard reaction mixture contained $6 \times 10^{-7} \mathrm{M}$ CLA, $5 \times 10^{-5} \mathrm{M}$ hypoxanthine, 65 units of xanthine oxidase (XOD), SOD $(0-20 \mathrm{ng} / \mathrm{ml})$, and $50 \mathrm{mM}$ Tris-HCl buffer containing $0.1 \mathrm{mM}$ EDTA at a $\mathrm{pH}$ of 7.8 , in a total volume of $3.0 \mathrm{ml}$. Chemiluminescence measurement was initiated by adding CLA to the reaction mixture without XOD; XOD was added to the mixture 2 min later. Chemiluminescence was then measured with a luminescence reader (BLR-102, Aloka, Tokyo, Japan) at $25^{\circ} \mathrm{C}$.

\section{Statistical analysis}

The results are presented as mean $\mathrm{SE}$. Statistical analysis was carried out by analysis of variance with Scheffe's test for multiple comparisons. A value of $\mathrm{p}<0.05$ was considered significant.

\section{Results}

\section{Plasma MDA content}

All three groups of diabetic rats showed significantly higher levels of plasma MDA than the control group. There were no significant differences between the diabetic groups (Fig. 1).

\section{Tissue MDA content}

The myocardial MDA content was significantly higher in the 4-week and 8- 


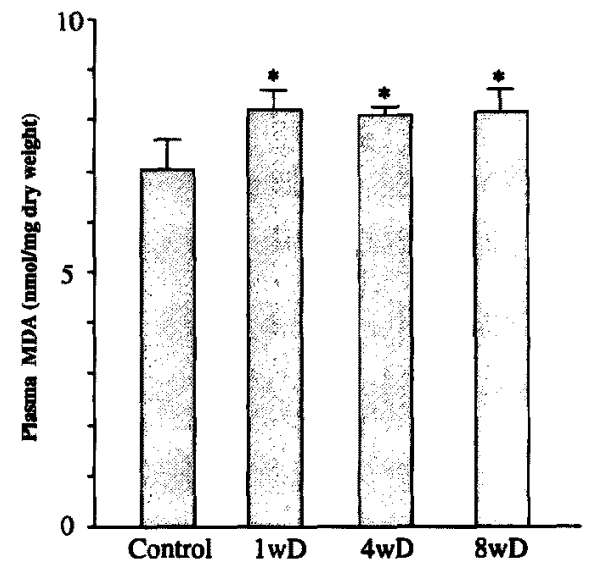

Fig. 1. Plasma MDA (malondialdehyde) content. Each bar represents the mean $\pm S E$ of data for 10 rats. $1 w D=1$-week diabetic rats; $4 w D=4$-week diabetic rats; $8 w \mathrm{D}=8$-week diabetic rats. ${ }^{*}<0.01$ compared with the control group.

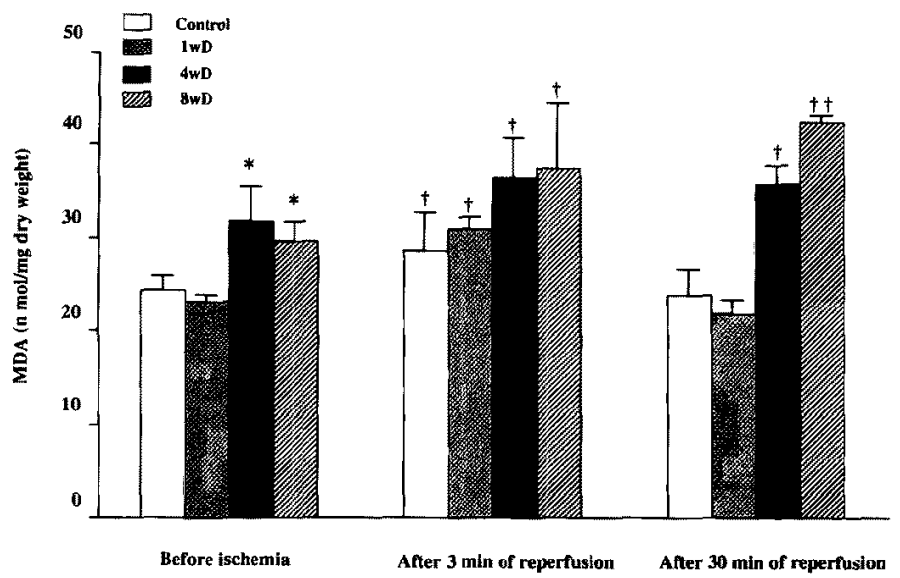

Fig. 2. Effects of diabetes and ischemia/reperfusion on myocardial MDA (malondialdehyde) content. Hearts were subjected to $20 \mathrm{~min}$ of global ischemia followed by $30 \mathrm{~min}$ of reperfusion. The MDA content was determined before ischemia and $3 \mathrm{~min}$ and $30 \mathrm{~min}$ after reperfusion. Each bar represents the meantSE of data for 5 to 7 hearts. $1 \mathrm{wD}=1$-week diabetic rats; $4 \mathrm{wD}=4$-week diabetic rats; $8 \mathrm{wD}=8$-week diabetic rats. $* p<0.05$ compared with the control group. $\dagger p<0.05, \quad \dagger p<0.01$ compared with preischemic values.

week diabetic groups, even in the preischemic state, compared with the control group and 1-week diabetic group (Fig. 2). Three minutes after reperfusion a marked increase in MDA levels was observed in all four groups.

Thirty minutes after beginning reperfusion, the MDA levels in the control and 1-week diabetic groups had returned to $98 \%$ and $95 \%$ of the preischemic levels, respectively. However, the MDA levels did not decrease during 
reperfusion in the 4 -week and 8-week groups $(112 \%$ and $143 \%$ of preischemic levels, respectively) (Fig. 2).

\section{SOD activity in cardiac muscle}

There were no significant differences in total SOD activity in cardiac muscle among the control group and 1-week and 4-week diabetic groups. In the 8 week diabetic group, SOD activity was significantly higher in the preischemic state compared with the other groups. In addition, this group displayed a significant decrease $30 \mathrm{~min}$ after reperfusion compared with the preischemic state (Fig. $3)$.

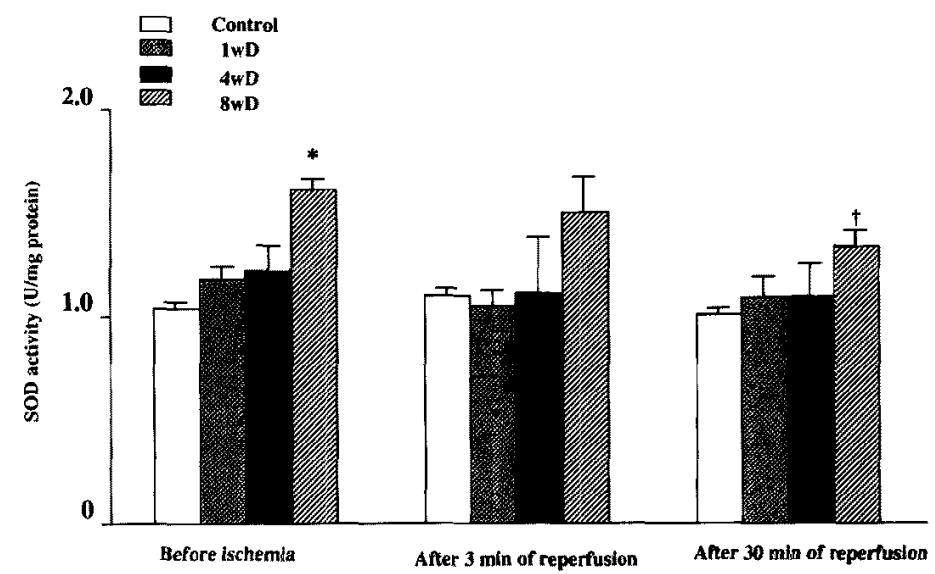

Fig. 3. Effects of diabetes and ischemia/reperfusion on myocardial SOD (superoxide dismutase) activity. Hearts were subjected to $20 \mathrm{~min}$ of global ischemia followed by $30 \mathrm{~min}$ of reperfusion. The SOD activity was determined before ischemia and 3 $\mathrm{min}$ and $30 \mathrm{~min}$ after reperfusion. Each bar represents the meantSE of data for 5 to 7 hearts. $1 \mathrm{wD}=1$-week diabetic rats; $4 \mathrm{wD}=4$-week diabetic rats; $8 \mathrm{wD}=8$-week diabetic rats. $* p<0.05$ compared with the control group. $\dagger p<0.05$ compared with preischemic values.

\section{Hemodynamic measurements}

Heart rate: Before ischemias, the heart rates of preparations from the 1week diabetic group did not differ significantly from controls (Table I). The heart rate was significantly depressed from control values in the 4-week diabetic group, and the heart rate in the 8-week diabetic group was significantly lower than in all three other groups. After $30 \mathrm{~min}$ of reperfusion, the heart rate was lower than preischemic values in control, 1-week and 4-week diabetic groups.

LVSP: There was no significant difference in LVSP between the control group and the 1-week diabetic group (Table I). In the preischemic state, LVSP was significantly lower in the 4-week and 8-week diabetic groups than in the 
Table I. Hemodynamic Data

\begin{tabular}{|c|c|c|c|c|c|c|c|c|}
\hline & \multicolumn{2}{|c|}{ Control $(n=8)$} & \multicolumn{2}{|c|}{$1 w D(n=7)$} & \multicolumn{2}{|c|}{$4 w D(n=6)$} & \multicolumn{2}{|c|}{$8 \mathrm{wD}(\mathrm{n}=6)$} \\
\hline & Pre & Post & Pre & Post & Pre & Post & Pre & Post \\
\hline $\begin{array}{l}\text { HR } \\
\text { (beats/min) }\end{array}$ & $298 \pm 31$ & $272 \pm 38 *$ & $272 \pm 14$ & $229 \pm 26^{*}$ & $261 \pm 27^{\dagger}$ & $228 \pm 20^{*}$ & $220 \pm 20^{\dagger+\ddagger 3}$ & $209 \pm 20$ \\
\hline $\begin{array}{l}\text { LVSP } \\
\text { (mmHg) }\end{array}$ & $110 \pm 6$ & $105 \pm 5$ & $114 \pm 4$ & $106 \pm 9$ & $91 \pm 6^{+1+4}$ & $92 \pm 7$ & $86 \pm 11^{1+* t}$ & $85 \pm 4$ \\
\hline $\begin{array}{l}\text { LVEDP } \\
\text { (mmHg) }\end{array}$ & $1.7 \pm 1.5$ & $4.3 \pm 2.1 *$ & $2.1 \pm 1.1$ & $4.4 \pm 0.9 *$ & $4.5 \pm 1.1^{\uparrow}$ & $4.4 \pm 1.1$ & $4.8 \pm 1.8^{\dagger \ddagger}$ & $5.8 \pm 1.8$ \\
\hline $\begin{array}{l}+\mathrm{dp} / \mathrm{dt} \\
(\mathrm{mmHg} / \mathrm{s})\end{array}$ & $3240 \pm 390$ & $3400 \pm 280$ & $2940 \pm 270$ & $2850 \pm 270$ & $2700 \pm 260$ & $2650 \pm 310$ & $2400 \pm 420^{\dagger t}$ & $2450 \pm 90$ \\
\hline $\begin{array}{l}-\mathrm{dp} / \mathrm{dt} \\
(\mathrm{mmHg} / \mathrm{s})\end{array}$ & $3050 \pm 260$ & $2650 \pm 360$ & $2780 \pm 180$ & $2330 \pm 240$ & $2050 \pm 190^{\dagger+t * t}$ & $2130 \pm 220$ & $1730 \pm 220^{t+\hbar}$ & $1650 \pm 170$ \\
\hline
\end{tabular}

$1 \mathrm{wD}=1$-week diabetic rats; $4 \mathrm{wD}=4$-week diabetic rats; $8 \mathrm{wD}=8$-week diabetic rats; Pre=before ischemia; Post=after $30 \mathrm{~min}$ of reperfusion; $\mathrm{HR}=$ heart rate; $\mathrm{LVSP}=$ left ventricular systolic pressure; $\mathrm{LVEDP}=\mathrm{left}$ ventricular end-diastolic pressure; $+\mathrm{dp} / \mathrm{dt}=$ maximum rate of left ventricular pressure rise; $-\mathrm{dp} / \mathrm{dt}=$ maximum rate of left ventricular pressure fall.

* $p<0.05$ compared with preischemic values.

${ }^{\dagger} \mathrm{p}<0.05, \quad$ t $\mathrm{p}<0.01$ compared with the control group.

$+p<0.05, \quad++p<0.01$ compared with the $1 w D$ group.

$\S p<0.05$ compared with the $4 \mathrm{wD}$ group.

control group. LVSP did not deteriorate during ischemia/reperfusion.

LVEDP: In the preischemic preparations, LVEDP was similar in the 1week diabetic and control groups (Table I). The 4-week and 8-week diabetic groups demonstrated significantly higher LVEDP values. After reperfusion, LVEDP increased significantly in the control and 1-week diabetic groups.

Maximum rate of left ventricular pressure change: The maximum rate of left ventricular pressure rise $(+\mathrm{dp} / \mathrm{dt})$ was significantly lower in the 8-week diabetic group compared with the control group. The maximum rate of the left ventricular pressure fall $(-\mathrm{dp} / \mathrm{dt})$ was significantly lower in the 4-week and 8-week diabetic groups.

In 8-week diabetic rats, indices of cardiac function showed no deterioration during ischemia/reperfusion.

\section{Discussion}

We evaluated the influence of diabetes on lipid peroxidation and scavenger induction and the effects of ischemia/reperfusion on lipid peroxidation, scavenger action, and cardiac function in isolated hearts. Plasma and myocardial levels of MDA, an indicator of lipid peroxidation, were elevated in the diabetic groups, and myocardial SOD activity was significantly elevated in 8-week diabetic rats. In hearts from both the control and diabetic animals, the tissue MDA concentration was elevated significantly from preischemic values during the first $3 \mathrm{~min}$ of 
reperfusion. Although it remained high in the 4-week and 8-week diabetic groups, no correlation with functional deterioration was observed.

Free radical-mediated oxidative damage has been implicated in diabetic tissue injury, including microangiopathy and metabolic disorders, ${ }^{3)}$ and it also contributes to atherosclerosis, especially in diabetic patients. When radical formation occurs in cell membranes, there may be a progressive disturbance of structural organization, which has a negative importance on cardiac function. To date, however, information on tissue levels of antioxidant enzymes and lipid peroxide in diabetic animals has been incomplete and equivocal. Biological tissues contain a variety of antioxidants, including dismutase, catalase, glutathione peroxidase, thiol compounds, and vitamins, which can protect the cell and its membranes against peroxidative deterioration. ${ }^{8-12)}$ In normal cells, SOD (which inhibits cellular damage by neutralizing superoxide radicals to $\mathrm{H}_{2} \mathrm{O}_{2},{ }^{13), 14)}$ ) is activated by low oxygen tension and excess production of superoxide radicals. $\mathrm{Al}$ though antioxidant enzymes like SOD play important roles as scavengers of free radicals, their activity can be gradually exhausted. ${ }^{15,16)}$ Matkovics et al reported a decreased SOD activity in rat hearts with streptozotocin-induced diabetes of 2 months duration. ${ }^{17)}$ Lammi-Keefe et al also reported a slight decrease in SOD activity in rat hearts 80 days after streptozotocin injection. ${ }^{18)}$ On the other hand, Asayama et al found both CuZnSOD and MnSOD levels to be unchanged in rat hearts 2 weeks after streptozotocin injection. ${ }^{19)}$ The discrepancies between these studies may be partly the result of variations in the methodology used for measuring SOD activity. The present study suggests that these changes are time-dependent because SOD activity increased from 4 to 8 weeks as a consequence of elevated lipid peroxidation.

The involvement of oxygen-derived free radicals in the pathogenesis of myocardial ischemia/reperfusion injury is well established. ${ }^{20-23)}$ Our data showed that the 8-week diabetic rats had high tissue MDA levels in the preischemic state and that MDA formation increased during reperfusion, despite an increased SOD activity. Increases in glycosylated proteins, ${ }^{15), 24)}$ alterations of phospholipids, ${ }^{25)}$ membrane damage ${ }^{19)}$ and depleted vitamin $\mathrm{E}^{26)}$ are believed to contribute to this increase in lipid peroxidation. In addition, the marked free radical formation during ischemia/reperfusion exceeded the scavenging ability of SOD, judged by its significant decrease after reperfusion.

Deterioration of cardiac function in the streptozotocin-induced diabetic rats corresponded to duration of diabetes, with the poorest cardiac function occurring in the 8-week diabetic group. However, this group also showed no change in relevant parameters between the preischemic and ischemia/reperfusion states. Functional abnormalities, such as decreases in heart rate, LVSP, and $\pm d p / d t$, have been observed in acute and chronic diabetic rat hearts. ${ }^{27-30)}$ Diabetic ani- 
mals have also been reported to be more susceptible to ischemic stress than nondiabetic animals. ${ }^{25), 317}$ However, our data indicated that the observed increase in MDA formation did not have a significant influence on heart function.

In conclusion, our results demonstrate that cardiac function in diabetic rats deteriorated during chronic diabetes, and that the deterioration was associated with lipid peroxidation. However, no changes in cardiac function-related parameters were found before ischemia and after reperfusion, suggesting that the diabetes-associated lipid peroxidation had little effect during ischemia/reperfusion. By contrast, parameters of cardiac function in nondiabetics decreased after reperfusion. Thus, the depressed cardiac function of diabetic rat hearts is unresponsive to ischemia/reperfusion.

\section{ACKNOWLedgment}

The authors gratefully acknowledge the expert secretarial and technical assistance of Miss Yoshie Mano.

\section{References}

1. McCord JM: Oxygen-derived free radicals in postischemic tissue injury. $\mathbf{N}$ Engl J Med 312: 159, 1985

2. Van der Vusse GJ, Reneman RS: Pharmacological intervention in acute myocardial ischemia and reperfusion. Trends Pharmacol Sci 6: 76, 1985

3. Jennings PE, Jones AF, Florkowski CM, Lunec J, Barnett AH: Increased diene conjugates in diabetic subjects with microangiopathy. Diabetic Med 4: 452, 1987

4. Nishigaki I, Hagihara M, Tsunekawa $H$, Maseki M, Yagi K: Lipid peroxide levels of serum lipoprotein fractions of diabetic patients. Biochem Med 25: 373, 1981

5. Neely JR, Liebermeister H, Battersby EJ, Morgan HE: Effect of pressure development on oxygen consumption by isolated rat heart. Am. J Physiol 212: 804, 1967

6. Yagi K: A simple fluorometric assay for lipoperoxide in blood plasma. Biochem Med 15: 212, 1976

7. Nakano M, Kimura H, Hara M, Kuroiwa M, Kato M, Totsune K, Yoshikawa T: A highly sensitive method for determining both $\mathrm{Mn}$ - and $\mathrm{Cu}-\mathrm{Zn}$ superoxide dismutase activities in tissues and blood cells. Anal Biochem 187: 277, 1990

8. Meerson FZ, Kagan VE, Kozlov YP, Belkina LM, Arkhipenko YV: The role of lipid peroxidation in pathogenesis of ischemic damage and the antioxidant protection of the heart. Basic Res Cardiol 77: 465, 1982

9. Shlafer M, Kane PF, Kirsh MM: Superoxide dismutase plus catalase enhances the efficacy of hypothermic cardioplegia to protect the globally ischemic, reperfused heart. J Thorac Cardiovasc Surg 83 : 830,1982

10. Slater TF: Mechanisms of protection against the damage produced in biological systems by oxygenderived radicals. in Ciba Foundation Symposium 65. Oxygen Free Radicals and Tissue Damage, Excerpta Medica, Amsterdam, p 143, 1979

11. Tappel AL, Dillard CJ: In vivo lipid peroxidation; measurement via exhaled pentane and protection by vitamin E. Fed Proc 40: 174, 1981

12. Tien M, Svingen BA, Aust SD: Superoxide dependent lipid peroxidation. Fed Proc 40: 179, 1981

13. Fridovich I: Superoxide dismutases. Adv Enzymol Relat Areas Mol Biol 41: 35, 1974

14. Fridovich I: Superoxide dismutașes. Annu Rev Biochem 44: 147, 1975

15. Chace KV, Carubelli R, Nordquist RE: The role of nonenzymatic glycosylation, transition metals, 
and free radicals in the formation of collagen aggregates. Arch Biochem Biophys 288: 473, 1991

16. Gupta M, Singal PK: Time course of structure, function, and metabolic changes due to an exogenous source of oxygen metabolites in rat heart. Can J Physiol Pharmacol 67: 1549, 1989

17. Matkovics B, Varga SI, Szabó L, Witas H: The effect of diabetes on the activities of the peroxide metabolism enzymes. Horm Metab Res 14: 77, 1982

18. Lammi-Keefe GJ, Swan PB, Hegarty PVJ: Evidence for increased peroxidative activity in muscles from streptozotocin-diabetic rats. Proc Soc Exp Biol Med 176: 27, 1984

19. Asayama K, Hayashibe H, Dobashi K, Niitsu T, Miyao A, Kato K: Antioxidant enzyme status and lipid peroxidation in various tissues of diabetic and starved rats. Diabetes Res 12: 85, 1989

20. Burton KP: Evidence of direct toxic effects of free radicals on the myocardium. Free Radic Biol Med 4: 15,1988

21. Flaherty JT, Weisfeldt ML: Reperfusion injury. Free Radic Biol Med 5: 409, 1988

22. Godin DV: Role of reactive oxygen derived radicals in ischemic heart disease. Can J Cardiol 5: 235, 1989

23. Simpson PJ, Mickelson JK, Lucchesi BR: Free radical scavengers in myocardial ischemia. Fed Proc 46: 2413,1987

24. Ceriello A, Giugliano D, Quatraro A, Dello Russo P, Lefebvre PJ: Metabolic control may influence the increased superoxide generation in diabetic serum. Diabetic Med 8: 540, 1991

25. Haider B, Ahmed SS, Moschos CB, Oldewurtel HA, Regan TJ: Myocardial function and coronary blood flow response to acute ischemia in chronic canine diabetes. Circ Res 40: 577, 1977

26. Karpen CW, Pritchard KA Jr, Arnold JH, Cornwell DG, Panganamala RV: Restoration of

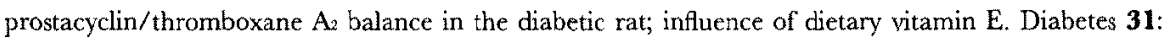
947,1982

27. Fein FS, Kornstein LB, Strobeck JE, Capasso JM, Sonnenblick EH: Altered myocardial mechanics in diabetic rats. Circ Res 47: 922, 1980

28. Penpargkul S, Schaible T, Yipintsoi T, Scheuer J: The effect of diabetes on performance and metabolism of rat hearts. Circ Res 47: 911, 1980

29. Rösen P, Windeck P, Zimmer HG, Frenzel H, Bürrig KF, Reinauer H: Myocardial performance and metabolism in non-ketotic, diabetic rat hearts; myocardial function and metabolism in viwo and in the isolated perfused heart under the influence of insulin and octanoate. Basic Res Cardiol 81: 620, 1986

30. Vadlamudi RVSV, Rodgers RL, McNeill JH: The effect of chronic alloxan- and streptozotocininduced diabetes in isolated rat heart performance. Can J Physiol Pharmacol 60: 902, 1982

31. Feuvray D, Idell-Wenger JA, Neely JR: Effects of ischemia on rat myocardial function and metabolism in diabetes. Circ Res 44: 322, 1979 